\title{
Alvos Moleculares dos Fármacos no Tratamento da COVID-19
}

\author{
Molecular Targets of Drugs in the Treatment of COVID-19
}

\author{
Irineu Ferreira da Silva Neto ${ }^{1}$ \\ Isadora Ellen Feitoza Ricardino ${ }^{1}$ \\ Maria Nathalya Costa Souza ${ }^{1}$ \\ Rafael de Carvalho Mendes ${ }^{1}$
}

${ }^{1}$ Faculdade de Medicina Estácio de Juazeiro do Norte, Juazeiro do Norte, CE, Brasil

\begin{abstract}
Resumo
Devido à pandemia da COVID-19, vários pesquisadores estão buscando estratégias farmacológicas para o tratamento dessa enfermidade. Neste artigo pretende-se expor os alvos farmacológicos mais relevantes encontrados na literatura e que estão frequentemente sendo utilizados no tratamento da COVID-19. Foi realizada uma revisão de literatura por meio de busca nas bases de dados eletrônicas: SciELO e PubMed, para tanto, utilizou-se os seguintes descritores: Fármacos "Drugs", Tratamento "Treatment" e COVID-19. Selecionou-se publicações entre dezembro de 2019 a junho de 2020. Entre os fármacos mais utilizados no tratamento da COVID-19, estão: Redemsivir, Favipiravir, Ribavirina, Arbidol, Hidroxicloroquina, Azitromicina, Interferon, combinado com beta-1b, e associação entre Lopinavir/Ritonavir. Os alvos dessas drogas incluem a inibição da RNA polimerase dependente, a fusão do vírus com a membrana da célula alvo, a acidificação endossômica e a exocitose viral e da protease do tipo papaína e 3C. Ressalta-se a importância de estudos controlados e específicos de acordo com cada país, visto que o perfil fisiológico da população se mostra diferente para cada uma.
\end{abstract}

Palavras-chave: COVID-19. Mecanismo de Ação. Tratamento.

\begin{abstract}
Having a COVID-19 pandemic, several researchers are looking for pharmacological strategies for the treatment of this disease. Objective: to expose the pharmacological results most found in the literature, frequently used in the treatment of COVID-19. A literature review was carried out, based on the electronic databases SciELO and PubMed, using the following descriptors: Fármacos "Drugs", Tratamento "Treatment" e COVID-19. Selected publications between December 2019 and June 2020. Among the products most used in the treatment of COVID-19 are: Redemsivir, Favipiravir, Ribavirin, Arbidol, Hydroxychloroquine, Azithromycin, Interferon combined with beta- $1 \mathrm{~b}$ and association between Lopinavir / Ritonavir. The effects of these drugs are inhibited by: dependent RNA polymerase, virus fusion with target cell membrane, endosomal acidification, viral exocytosis and papain and $3 \mathrm{C}$ protease. The importance of controlled studies and changes according to each country is emphasized, since the physiological profile of each population differs from another.
\end{abstract}

Keywords: COVID-19. Mechanism of Action. Treatment.

Área Tecnológica: Farmacologia. 


\section{Introdução}

A COVID-19, causada pelo novo coronavírus (SARS-CoV-2), se espalhou pelo mundo, tornando-se uma emergência de grande preocupação internacional. A infecção pelo vírus SARS-CoV-2 causa complicações de doenças respiratórias graves, semelhantes ao coronavírus da síndrome respiratória aguda grave. A transmissão de humano para humano ocorre por meio de gotículas, das mãos ou de superfícies contaminadas, com tempos de incubação de 2-14 dias, e, entre as principais medidas para o controle, destaca-se o diagnóstico precoce, o isolamento social rígido e os tratamentos de suporte, que são essenciais para curar os pacientes (ZHAI et al., 2020).

Em 3 de fevereiro de 2020, o Brasil declarou a COVID-19 uma Emergência de Saúde Pública (ESP), mas foi apenas no dia 6 de fevereiro que o Ministério da Saúde aprovou a lei n. 13.979 (Lei de Quarentena), a qual impôs medidas destinadas a proteger a comunidade, além de lidar com a ESP desencadeada pelo SARS-CoV-2. Entre as medidas impostas, foram incluídas estas: isolamento; quarentena; notificação obrigatória, estudo epidemiológico ou investigação; exumação, necropsia, cremação e manejo de cadáveres; restrição excepcional e temporária à entrada e saída do país; e requisição de bens e serviços de pessoas (CRODA et al., 2020).

Rapidamente houve expansão do conhecimento sobre a virologia do SARS-CoV-2, o que forneceu um número significativo de potenciais alvos de drogas. O estudo de Sanders et al. (2020) expõe que a terapia mais promissora é o Remdesivir, após se mostrar potente em atividade in vitro contra o SARS-CoV-2, mas, até o momento da sua publicação, o medicamento não havia sido aprovado pela Food and Drug Administration (FDA) dos Estados Unidos da América (EUA), pois ainda estavam sendo testado em estudos randomizados.

A pandemia de COVID-19 representa a maior crise de saúde pública global desde o surto de gripe pandêmica de 1918, e, como se trata de um novo vírus, vários agentes antivirais usados anteriormente para tratar outras infecções por coronavírus, como SARS e MERS, estão sendo considerados os primeiros potenciais candidatos para tratar a COVID-19. Diversos agentes foram utilizados no início do surto na China e, posteriormente, em todo o mundo, conforme foi relatado em várias diretrizes e recomendações terapêuticas. Concomitantemente a isso, um grande número de ensaios clínicos foi lançado para investigar as possíveis terapias eficazes para a COVID-19, destacando-se a necessidade urgente de se obter, o mais rápido possível, as evidências de alta qualidade (ESPOSITO; NOVIELLO; PAGLIANO, 2020).

Ainda não existe tratamento antiviral eficaz específico para a doença causada pelo SARS-CoV-2, apesar de a maioria dos pacientes possuir apenas sintomas leves ou moderados, entre $5 \%$ e $10 \%$ podem ter um quadro mais grave e potencialmente fatal, é daí que surge a necessidade urgente de medicamentos que sejam eficazes. Os cuidados de suporte otimizados continuam a base da terapia no tratamento dessa enfermidade. Muitos ensaios clínicos ainda em andamento e vários agentes antivirais e imunomoduladores estão em estágios de avaliação para a COVID-19, mas, ainda, é necessário encontrar um tratamento antiviral eficaz que utilize estudos controlados e randomizados, já que certos agentes estão sendo usados em todo o mundo com base em evidências in vitro, extrapoladas ou em estudos observacionais (ŞIMŞEK YAVUZ; ÜNAL, 2020). 
Diante do que foi exposto, este estudo tem como objetivo expor os alvos farmacológicos mais relevantes encontrados na literatura e que estão frequentemente sendo utilizados no tratamento da COVID-19.

\section{Metodologia}

A presente revisão de literatura utilizou-se de uma vasta busca por pesquisas científicas nas bases de dados: SciELO (Scientific Electronic Library Online) e PubMed (National Library of Medicine). Nessas bases foram utilizados os seguintes descritores: Fármacos "Drugs", Tratamento "Treatment" e COVID-19, sendo combinados pelo operador booleano "AND", com o objetivo de refinar a busca dos estudos que ocorreu no mês de junho de 2020.

Para seleção dos artigos, estabeleceu-se aqueles datados entre dezembro 2019 até junho de 2020, dentro dos idiomas português e inglês, e que fossem de caráter exploratório, descritivo e experimental. Após a seleção das publicações a serem utilizadas, por meio da leitura de várias pesquisas pelos autores, buscou-se artigos que preenchessem os seguintes critérios de inclusão: apresentar os idiomas designados, estar dentro das datas selecionadas, expor pelo menos dois descritores específicos, estar presente nas bases de dados apresentadas e se enquadrar em pesquisas experimentais, exploratórias ou descritivas. Como caráter de exclusão, optou-se pelas publicações que não fossem obtidas por meio da opinião de especialistas.

No processo de seleção, foram identificados 8.379 (oito mil trezentos e setenta e nove) estudos nas bases de dados, selecionados por meio da combinação dos descritores: COVID-19 "AND" Tratamento em português e inglês; Drugs "AND" Treatment "AND" COVID-19. A quantidade de estudos encontrados está representada no Quadro 1.

Quadro 1 - Estudos encontrados nas bases de dados

\begin{tabular}{|c|c|c|c|}
\hline Base de dados & $\begin{array}{c}\text { COVID-19 “AND” } \\
\text { Tratamento }\end{array}$ & $\begin{array}{c}\text { COVID-19 “AND” } \\
\text { Treatment }\end{array}$ & $\begin{array}{c}\text { Drugs “AND” Treatment } \\
\text { "AND” COVID-19 }\end{array}$ \\
\hline PubMed & 0 & 7.433 & 853 \\
\hline SciELO & 33 & 53 & 7 \\
\hline Total & 33 & 7.486 & 860 \\
\hline
\end{tabular}

Fonte: Dados da pesquisa (2020)

Os resumos desses estudos foram avaliados a partir da aplicação dos critérios de inclusão e de exclusão determinados pelos autores. A seleção foi realizada por dois avaliadores independentes e, caso houvesse divergência, um terceiro avaliador daria o consenso final. Posteriormente, foram pré-selecionados 53 estudos para serem lidos na íntegra, levando à exclusão de 31 trabalhos e à escolha de 22, destes, 8 tratavam sobre estudos clínicos e 14 evidenciavam o mecanismo de ação dos fármacos a partir do foco central desta pesquisa, que são aqueles que apresentam indícios sobre os alvos moleculares dos fármacos no tratamento da COVID-19. 


\section{Resultados e Discussão}

A identificação e descoberta da sequência genética do novo coronavírus foi de fundamental importância para que pesquisadores e cientistas da área da saúde e afins pudessem obter um certo nível de embasamento teórico para buscar as formas de tratamento e, até mesmo, a prevenção da infecção pelo SARS-CoV-2. Tanto o tratamento hospitalar quanto os estudos de desenvolvimento de uma vacina são baseados em fármacos e em formas de imunização já utilizados em doenças virais (ou até mesmo bacterianas), em que o agente patogênico possui certa similaridade com o novo coronavírus (WANG et al., 2020).

Na pesquisa de De Souza Morais et al. (2020), foi relatada a necessidade de uma triagem maior para definição da ação terapêutica e a indicação dos fármacos no tratamento da COVID-19, já que, até a publicação de seu estudo, havia apenas evidências limitadas, o que dificultava as conclusões. Relatou-se que, durante a sua pesquisa, foram encontrados apenas pequenos testes em pacientes com COVID-19, o que mostra a evolução das pesquisas, já que, mesmo em um curto período de tempo, houve um aumento considerável de publicações acerca dos estudos clínicos no tratamento dessa enfermidade. Aos poucos, as pesquisas foram sendo realizadas para avaliar a eficiência diante da COVID-19, como será abordado nesta pesquisa. Ressalta-se que a geodistribuição dos estudos clínicos de fármacos utilizados no tratamento da COVID-19 concentra-se, principalmente, em um único país, o que evidencia a baixa interação internacional, mesmo sendo um problema de saúde pública mundial (QUINTELLA et al., 2020).

Ressalta-se que há vários estudos sendo realizados ao mesmo tempo em todo o mundo e são diversos os medicamentos já existentes no mercado, por isso, a seguir, estão relacionados os estudos com os fármacos mais relevantes e suas respectivas metodologias e resultados frente ao tratamento da COVID-19.

No estudo de Grein et al. (2020), os autores analisam o Remdesivir em uma base de uso compassivo a pacientes hospitalizados com COVID-19. Os pacientes receberam um curso de 10 dias com Remdesivir, consistindo em 200 mg administrados por via intravenosa no primeiro dia, seguidos por $100 \mathrm{mg}$ diariamente nos 9 dias restantes de tratamento. Nesse estudo, observou-se que, no coorte de pacientes hospitalizados com COVID-19 grave tratados com Remdesivir de uso compassivo, houve melhora clínica em 36 dos 53 pacientes hospitalizados (68\%).

Já na pesquisa de Wang et al. (2020), os pacientes foram divididos aleatoriamente em uma proporção de 2:1 para Remdesivir intravenoso (200 mg no dia 1, seguido por $100 \mathrm{mg}$ nos dias 2-10 em infusões diárias únicas) ou no mesmo volume de infusões de placebo por 10 dias. Embora não sejam estatisticamente significativos, os pacientes que receberam Remdesivir tiveram um tempo de melhora clínica numericamente mais rápido do que aqueles que receberam placebo, isso em pacientes com duração dos sintomas de 10 dias ou menos.

Cai et al. (2020) avaliaram outros medicamentos, no estudo desses autores, foram incluídos pacientes com COVID-19 confirmado em laboratório que receberam Favipiravir (FPV) oral (dia 1: $1600 \mathrm{mg}$ duas vezes ao dia; dias 2-14: $600 \mathrm{mg}$ duas vezes ao dia) combinado com interferon (IFN) - $\alpha$ por inalação de aerossol (5 milhões de $U$ duas vezes ao dia). A regressão multivariável de Cox mostrou que o FPV estava independentemente associado a uma depuração viral mais rápida. Além disso, menos reações adversas foram encontradas no grupo de pacientes que utilizou FPV do que no controle. Nesse estudo de controle aberto e não randomizado, o FPV mostrou 
efeitos de tratamento significativamente melhores na COVID-19 em termos de progressão da doença e taxas de recuperação.

Cao et al. (2020) dividiram os pacientes aleatoriamente em uma proporção de 1:1 para receber Lopinavir-Ritonavir (400 mg e $100 \mathrm{mg}$, respectivamente) duas vezes por dia, durante 14 dias. O desfecho primário foi o tempo para a melhora clínica, definida como o tempo entre a randomização e a melhoria de dois pontos em uma escala ordinal de sete categorias, ou a alta do hospital, o que ocorreu primeiro. Em pacientes adultos hospitalizados com COVID-19 grave, nenhum benefício foi observado com o tratamento com Lopinavir-Ritonavir, além do tratamento padrão.

Esses dados são semelhantes aos encontrados por Zhu et al. (2020), pois, no estudo deles, 50 pacientes com COVID-19 confirmado por laboratório foram divididos em dois grupos: incluindo o grupo Lopinavir/Ritonavir (34 casos) e o grupo Arbidol (16 casos). O grupo Lopinavir/ Ritonavir recebeu 400 mg/100 mg duas vezes por dia durante uma semana, enquanto o grupo Arbidol recebeu 0,2 g de Arbidol três vezes ao dia. Os pacientes do grupo Arbidol tiveram uma duração mais curta do teste de RNA positivo para o vírus em comparação com os do grupo Lopinavir/Ritonavir $(\mathrm{P}<0,01)$. Além disso, nenhum efeito colateral aparente foi encontrado nos dois grupos. Em conclusão, os dados indicam que a monoterapia com Arbidol pode ser superior ao Lopinavir/Ritonavir no tratamento da COVID-19.

Além dos estudos supracitados sobre o Lopinavir/Ritonavir, Hung et al. (2020) encontraram resultados semelhantes, no estudo desses autores, os pacientes foram divididos aleatoriamente (2:1) em uma combinação de 14 dias de Lopinavir 400 mg e Ritonavir 100 mg a cada 12 horas, Ribavirina 400 mg a cada 12 horas e três doses de 8 milhões de UI de interferon beta-1b em dias alternados, ou aos 14 dias de 400 mg de Lopinavir e 100 mg de Ritonavir a cada 12 horas (grupo controle). A terapia antiviral tripla precoce foi segura e superior ao Lopinavir-Ritonavir sozinho no alívio dos sintomas, na duração do derramamento viral e da permanência hospitalar em pacientes com COVID-19 de leve a moderado.

Gautret et al. (2020) realizaram um estudo observacional não controlado, não comparativo, em um coorte de 80 pacientes com infecção relativamente leve tratados com uma combinação de Hidroxicloroquina e Azitromicina por um período de pelo menos três dias, com três medidas principais: resultado clínico, contagiosidade avaliada por PCR e cultura e tempo de permanência na unidade de doenças infecciosas (UDI). Todos os pacientes melhoraram clinicamente, exceto um paciente de 86 anos que morreu e um paciente de 74 anos ainda em terapia intensiva. Observou-se uma queda rápida da carga viral nasofaríngea, com $83 \%$ de negativos no dia 7 e $93 \%$ no dia 8. As culturas de vírus das amostras respiratórias dos pacientes foram negativas em $97,5 \%$ dos pacientes no dia 5 . Consequentemente, os pacientes puderam receber alta rapidamente da UDI com um tempo médio de permanência de cinco dias.

Já Tang et al. (2020) avaliaram 150 pacientes internados no hospital com COVID-19 confirmado laboratorialmente que foram incluídos na intenção de tratar a análise (75 pacientes designados para a Hidroxicloroquina junto com o padrão de atendimento, e 75 apenas ao padrão de atendimento). Hidroxicloroquina administrada em uma dose inicial de $1.200 \mathrm{mg}$ por dia durante três dias, seguida por uma dose de manutenção de 800 mg por dia (duração total do tratamento: duas ou três semanas, para pacientes com doença leve a moderada ou grave, respectivamente). A administração de Hidroxicloroquina não resultou em uma probabilidade 
significativamente maior de conversão negativa do que o padrão de atendimento isolado em pacientes internados no hospital com COVID-19 leve a moderada, persistente, principalmente. Os eventos adversos foram maiores nos pacientes que utilizaram a Hidroxicloroquina em comparação aos que não utilizaram.

Ao avaliar os estudos clínicos que já foram realizados no tratamento da COVID-19, constata-se que existem tanto resultados que se assemelham quanto estudos que divergem, o que expõe a necessidade de se estudar especificamente uma conduta clínica para cada paciente, levando-se em consideração seus sinais e sintomas com o intuito de ter uma clínica segura e eficiente.

No estudo de Quintella et al. (2020), ao avaliarem os fármacos que são utilizados no tratamento da COVID-19, expõem as várias classes recorrentemente empregadas, que incluem: antimaláricos, antivirais, anti-inflamatórios, antibióticos, anticoagulantes, anticorpos, imunomoduladores e outros; dados que se assemelham aos encontrados no presente estudo. Vários estudos clínicos ainda estavam em andamento utilizando diferentes tipos de fármacos, e, como forma de continuidade, neste estudo, foram incluídos os resultados desses testes. Nesta pesquisa, foram incluídos novos candidatos utilizados na terapia dessa enfermidade, já que, aos poucos, vão surgindo novas hipóteses e suas averiguações com o intuito de amenizar o efeito negativo da pandemia. Aqueles fármacos que se mostraram promissores, agora, estão sendo avaliados para definir uma dosagem e segurança específicas para o tratamento da COVID-19, o que, consequentemente, demonstra a evolução dos tratamentos utilizados nessa enfermidade

Além dos estudos clínicos já realizados, outros ainda seguem em andamento, como é o caso de pesquisa com vitamina $\mathrm{C}$, na qual está sendo realizado um ensaio clínico randomizado multicêntrico controlado (LIU et al., 2020). A Triiodotironina também está sendo avaliada por meio de um estudo de fase II, paralelo, multicêntrico, prospectivo, randomizado, duplo-cego e controlado por placebo (PANTOS et al., 2020).

Existem também na literatura os projetos de testes a serem realizados para avaliar a segurança e eficácia de outros medicamentos, alguns deles como terapias complementares, como é o caso de Bemcentinibe, MEDI3506, Acalabrutinibe, Zilucoplan e Heparina Nebulizada. Nesse caso, a pesquisa é dividida em dois estágios, se o Estágio 1 fornecer evidências de eficácia e segurança aceitável, o candidato entrará no Estágio 2, no qual um total de aproximadamente 126 pacientes serão recrutados para cada subprotocolo do braço do estudo (WILKINSON et al., 2020). No caso da imunomodulação, eles estão avaliando a eficácia do novo agente imunomodulador EDP1815 (LU et al., 2020).

Além desses medicamentos já citados, os psicofármacos também se mostram candidatos, como é o caso da Clorpromazina (CPZ), um derivado da fenotiazina, que também é conhecida por sua atividade antiviral por meio da inibição da endocitose mediada pela clatrina. Esse redirecionamento da $\mathrm{CPZ}$ para sua atividade anti-SARS-CoV-2 pode oferecer uma estratégia alternativa e rápida para aliviar a gravidade da infecção (PLAZE et al., 2020), ou a hipótese apoia o tratamento de infecções por coronavírus com Oseltamivir, o que pode ser relevante para a gestão da atenção primária da COVID-19 (COENEN et al., 2020). Destaca-se, ainda, a utilização de células-tronco da polpa dentária humana (DPSCs) alogênicas no tratamento da pneumonia grave causada por COVID-19. Essa avaliação está sendo realizada em um único centro, do tipo triplo-cego, randomizado, controlado por placebo e por um grupo paralelo (YE et al., 2020). 


\subsection{Alvos Moleculares dos Fármacos Utilizados na COVID-19}

O SARS-CoV-2 consiste em um vírus envolto por RNA de fita simples e tem como alvo infectar as células por meio da proteína do pico estrutural viral (S), capaz de se ligar ao receptor da enzima conversora de angiotensina II. Assim, as partículas do vírus utilizam receptores de células hospedeiras e endossomas para entrar nas células. Uma vez dentro da célula, são sintetizadas poliproteínas virais, as quais codificam o complexo replicase transcriptase e, a partir de então, o vírus sintetiza RNA por meio de sua RNA polimerase dependente, que é formada causando a montagem e a liberação de partículas virais (ZHENG, 2020).

Dessa forma, essas etapas do ciclo viral fornecem possíveis mecanismos para as terapias medicamentosas. Os alvos promissores de drogas incluem proteínas não estruturais, tendo como, por exemplo, a protease do tipo 3-quimotripsina, papaína protease, RNA polimerase dependente de RNA, os quais compartilham homologia com outros novos coronavírus (nCoVs). Alvos adicionais de drogas ainda podem incluir: impedir a entrada viral, além da regulação da resposta imunológica (SANDERS et al., 2020). No Quadro 2 encontram-se relacionados os principais fármacos e os seus respectivos mecanismos de ação.

Quadro 2 - Relação dos fármacos e seus mecanismos de ação

\begin{tabular}{|c|c|}
\hline FÁRMACo & \multicolumn{1}{|c|}{ MecANISMo DE AÇão } \\
\hline Remdesivir & \\
\hline Favipiravir (FPV) & Inibição da RNA polimerase dependente \\
\hline Ribavirina & \\
\hline Arbidol & Inibição da fusão do vírus com a membrana da célula alvo \\
\hline Hidroxicloroquina & Inibição da acidificação endossômica \\
\hline Azitromicina & Potencializa o efeito da Hidroxicloroquina \\
\hline Interferon beta-1b & Inibição da exocitose viral \\
\hline Lopinavir-Ritonavir & Inibição da protease do tipo papaína e protease do tipo 3C \\
\hline
\end{tabular}

Fonte: Dados da pesquisa (2020)

\subsubsection{Remdesivir}

O Remdesivir (RDV) é um análogo de nucleotídeo e a forma trifosfato de RDV, ou seja, RDV-TP está sendo utilizado como substrato para muitos complexos virais da RNA polimerase dependente de RNA (RdRp) e tem sido relatado como inibidor da síntese de RNA viral por um mecanismo específico para todos os três coronavírus (MERS-CoV, SARS-CoV e SARS-CoV-2). Observa-se que o RDV-TP se assemelha à molécula de trifosfato de adenosina (ATP) e compete com o nucleotídeo durante a síntese do RNA viral. O grupo hidroxila 3' do RDV-TP forma uma ligação fosfodiéster com o próximo nucleotídeo, mas termina a formação da síntese do RNA viral em três nucleotídeos, precisamente na posição i + 3 (SAHA et al., 2020).

A atividade antiviral do Remdesivir, interagindo estericamente com o RdRp viral para induzir o término tardio da cadeia, foi demonstrada in vitro contra múltiplos coronavírus. O Remdesivir também demonstrou perturbar a função pan-CoV RdRp, inibindo a replicação viral, mesmo em ambientes com atividade intacta de revisão de exonucleases, emprega-se ainda a potência 
antiviral do medicamento por meio do término prematuro da síntese de RNA (EASTMAN et al., 2020).

Em um estudo que avaliou a carga viral de SARS-CoV-2 em esfregaços nasofaríngeos de 21 pacientes no início e durante o tratamento com Remdesivir, o RT-PCR mostrou que todos esses pacientes se tornaram negativos em uma mediana de 12 dias após o início de tratamento. Isso está de acordo com o rápido declínio da carga viral observado em um único paciente tratado com Remdesivir nos Estados Unidos, o que pode ser considerada com cautela uma resposta virológica positiva, visto que um estudo realizado em Wuhan mostrou que a duração mediana de eliminação viral entre os pacientes que sobreviveram à infecção por SARS-CoV-2 foi de 20 dias. Dessa forma, ressalta-se que o tratamento com Remdesivir pode ter um efeito benéfico na pneumonia por SARS CoV-2, especialmente no caso de pacientes não gravemente enfermos (ANTINORI et al., 2020).

\subsubsection{Favipiravir (FPV)}

O Favipiravir é um pró-fármaco ribosilado e fosforilado que forma dentro das células o metabólito ativo favipiravir ibofuranosil-5'-trifosfato (T-705-RTP). O T-705-RTP compete com os nucleosídeos da purina e interfere na replicação viral por incorporação no RNA do vírus e, portanto, potencialmente inibe a RNA polimerase dependente de RNA ( $\mathrm{RdRp}$ ) dos vírus com RNA. Já se mostrou eficiente ao inibir a RdRp do vírus influenza com uma concentração inibitória IC de $0,022 \mu \mathrm{g} / \mathrm{mL}$, mas não afeta as subunidades $\alpha, \beta$ e $\gamma$ das polimerases de DNA humano em até $100 \mu \mathrm{g} / \mathrm{mL}$. Além da inibição do vírus influenza, o Favipiravir mostra efeitos inibitórios em uma ampla gama de vírus RNA (DU; CHEN, 2020). Possui ainda atividade contra o vírus influenza, resistentes ao Oseltamivir e Zanamivir, vários agentes da febre hemorrágica viral e SARS-CoV-2 in vitro (COOMES; HAGHBAYAN, 2020).

O Favipiravir demonstra um perfil de segurança favorável em relação a eventos adversos totais e graves. No entanto, permanecem as preocupações de segurança: hiperuricemia e teratogenicidade que ainda não foram estudadas de forma adequada. Pode ser seguro e tolerável no uso em curto prazo, mas são necessárias mais evidências para avaliar os efeitos do tratamento em longo prazo. Dadas as limitações das evidências e as questões de segurança não resolvidas, justifica-se cautela no uso generalizado de Favipiravir para pacientes com COVID-19 (PILKINGTON; PEPPERRELL; HILL, 2020).

\subsubsection{Lopinavir-Ritonavir}

Lopinavir/Ritonavir (LPV/RTV) são inibidores da protease antirretroviral usados em combinação para o tratamento da infecção pelo vírus da imunodeficiência humana (HIV). O RTV é usado em conjunto com o LPV para aumentar a meia-vida do LPV por meio da inibição do citocromo P450 e age apenas como seu potenciador farmacocinético. O LPV atua contra a protease viral do tipo 3-quimotripsina e foi relatado com resultados promissores contra SARS-CoV-1 e MERS-CoV (LU et al., 2020). O Lopinavir, quando combinado com Ritonavir, melhora a média da concentração plasmática mínima de Lopinavir (GUL et al., 2020).

Em comparação ao tratamento apenas com drogas adjuvantes associadas à pneumonia, o tratamento combinado com (LPV/RTV) e drogas adjuvantes tem um efeito terapêtico mais 
evidente na redução da temperatura corporal e no restabelecimento dos mecanismos fisiológicos normais, sem efeitos tóxicos e colaterais evidentes. Diante dessas conclusões, sugere-se que o uso de (LPV/RTV) associado a medicamentos adjuvantes seja utilizado no tratamento clínico de pacientes com COVID-19 (YE et al., 2020).

\subsubsection{Arbidol}

O Arbidol, também conhecido como Umifenovir, é utilizado na Rússia e na China em tratamentos de infecções por vírus influenza e também é patenteado para tratamento com SARS. Possui como mecanismo antiviral contra Influenza A e B a inibição da fusão viral com a membrana-alvo, o que bloqueia a entrada do vírus na célula (ROSA; SANTOS, 2020).

Em estudos realizados in vitro com o Arbidol, pode-se comprovar a sua ação frente à replicação viral precoce para SARS-CoV, e, além disso, foi observado que a combinação entre Arbidol, Lopinavir e Ritonavir está associada, em pacientes sem uso de ventilação, a uma taxa de conversão negativa do teste do coronavírus em 7 e 14 dias, quando comparado com a terapia utilizando apenas LPV/RTV. Os estudos mostram também que a combinação de Arbidol e LPV/RTV está relacionada com uma melhora significativa dos sinais e dos sintomas (DENG et al., 2020).

A dinâmica molecular e a análise estrutural mostraram que a glicoproteína de pico do SARS-CoV-2 é o alvo da droga para Arbidol e sugere-se o modo potencial de ligação da droga com resíduos de interação-chave e mecanismo de ação, pelo qual esse fármaco pode efetivamente bloquear ou impedir a trimerização da glicoproteína de pico do SARS-CoV-2, que é a chave para a adesão e a entrada celular. O bloqueio da trimerização também provoca a formação de vírus descobertos ou imaturos, que são menos infecciosos (VANKADARI, 2020).

\subsubsection{Hidroxicloroquina e Azitromicina}

A cloroquina é um ionóforo de zinco e aumenta significativamente os níveis intracelulares deste. Em um estudo relatado pelos Centros de Controle e Prevenção de Doenças dos Estados Unidos (CDC), a cloroquina parece interferir na glicosilação terminal da Enzima Conversora de Angiotensina II (ECA II), além da elevação do pH endossômico. A ECA II é o receptor usado pelo vírus SARS-COV para entrar nas células. Os autores concluíram que o medicamento tinha um possível uso profilático e terapêutico contra culturas de células SARS-COV-1. A HCQ é o derivado menos tóxico da cloroquina. Num estudo in vitro, verificou-se que ele foi mais potente que a cloroquina contra a COVID-19 (GUL et al., 2020). De acordo com um estudo, foi demonstrado que a azitromicina (500 mg no dia 1, seguida de $250 \mathrm{mg}$ por dia no dia 2-5) reforça significativamente a eficácia da Hidroxicloroquina (JEAN; LEE; HSUEH, 2020).

É postulado ainda que a Hidroxicloroquina exerce uma atividade antiviral direta, aumentando o pH intracelular, resultando na diminuição da fusão fagossomo-lisossomo, prejudicando a glicosilação do receptor viral. Além disso, tem efeito imunomodulador ao inibir a sinalização do receptor toll-like, diminuindo a produção de citocinas, especialmente IL-1 e IL-6 (ARSHAD et al., 2020).

\subsubsection{Interferon beta- $1 \mathrm{~b}$}


Os interferons (IFNs) são proteínas naturais produzidas por células do sistema imunológico que possuem propriedades antivirais, antiproliferativas e imunomoduladoras. Os interferons betas representam a primeira classe de terapias modificadoras de doenças (DMTs), contribuindo consideravelmente para a compreensão dos mecanismos imunomoduladores. O interferon beta humano (hIFN- $\beta$ ) é uma glicoproteína hidrofóbica que contém 166 aminoácidos produzidos por fibroblastos (SILVA et al., 2019). O IFN $\beta$-1b liga-se aos receptores de interferon tipo I, e, aproximadamente, 100 proteínas imunomoduladoras e antivirais são ativadas por sua fosforilação e dimerização (SIRBU et al., 2020).

$\mathrm{O}$ tratamento com interferon $\beta$ (IFNb) - $1 \mathrm{~b}$, um agente imunomodulador, demonstrou resultar em melhora clínica entre os saguis infectados por MERS-CoV, mas os benefícios do IFNb-1b para pacientes com SARS permanecem incertos (JEAN; LEE; HSUEH, 2020). Esse tratamento ainda pode acelerar a depuração e inibir a exocitose viral (LIPWORTH; KUO; CHAN, 2020).

\subsubsection{Ribavirina}

A Ribavirina é um análogo na guanosina que interfere na replicação dos vírus RNA e DNA, porém a atividade antiviral desse fármaco não está limitada apenas à sua interferência com as polimerases, o que significa dizer que a estrutura da Ribavirina também vai interferir no capeamento de RNA que é dependente da guanosina natural para impossibilitar a degradação do RNA. Além disso, esse medicamento ainda inibe a geração natural de guonosina, o que impede diretamente a inosina monofosfato desidrogenase de uma maneira que é fundamental para a produção do precursor da guanina na guanosina (LU et al., 2020).

Dessa forma, a Ribavirina promove ainda mais uma desestabilização do RNA viral. Esse fármaco ainda possui uma atividade antiviral a partir da modulação do sistema imunológico do paciente, a partir do bloqueio incompleto que causa na replicação do vírus, levando a mutações aleatórias capazes de aumentar a resposta do sistema imune. Para o uso na COVID-19, indica-se dosagem via endovenosa ou oral (KHALILI et al., 2020).

As propriedades antivirais multimodais da Ribavirina podem limitar a replicação viral, reduzindo a carga viral do paciente, danos subsequentes ao tecido patológico e o risco de transmissão. Não há conhecimento sobre a dosagem necessária para experimentar cada um dos mecanismos únicos de ação da Ribavirina, e também não se sabe se o limiar relativo para a atividade irá variar entre diferentes populações de pacientes e contextos clínicos. Uma inibição replicativa viral direta não é o determinante exclusivo da atividade antiviral multimodal, e os múltiplos mecanismos de ação desse fármaco provavelmente suportam sua longevidade $e$ qualidade como recurso clínico (KHALILI et al., 2020).

Na Figura 1 pode-se observar a quantidade de ensaios clínicos que estão sendo realizados até o momento de produção deste artigo e quais são os principais fármacos estudados contra a COVID-19 no mundo, sendo que a maioria deles utiliza a Hidroxicloroquina. 
Figura 1 - Quantidade de ensaios clínicos com os principais fármacos estudados contra a COVID-19 no mundo

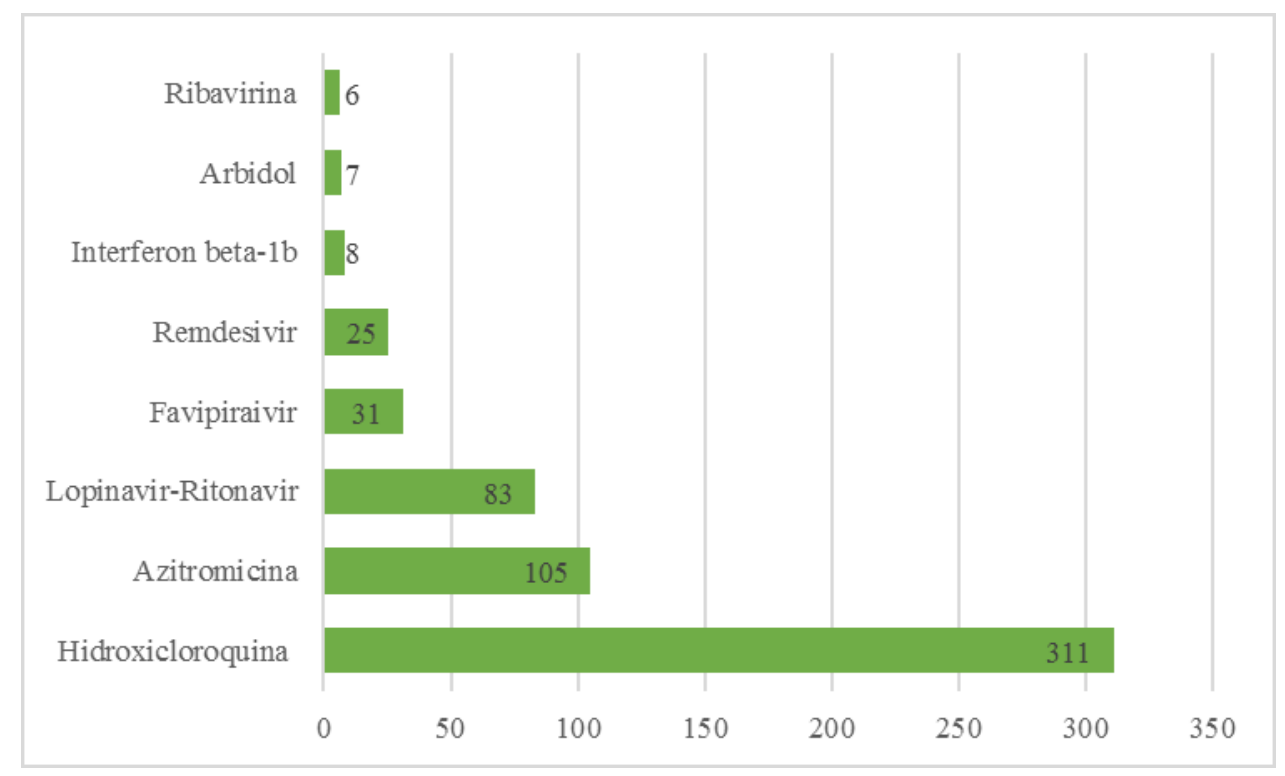

Fonte: Dados da pesquisa (2020)

\subsection{Terapias e Hipótese Alternativas para a COVID-19}

Como já citado, há poucos estudos randomizados que demostram um tratamento antiviral eficaz para o tratamento da COVID-19. A respostas imunes do organismo ao novo coronavírus são diferentes para cada indivíduo, o que pode resultar em diferentes quadros clínicos e, consequentemente, diferentes respostas ao tratamento e às vacinas (YU; WANG; SHEN, 2020). É por isso que novas abordagens estão sendo estudadas, utilizando-se de hipóteses a partir de potenciais efeitos imunomoduladores de determinadas substâncias, antioxidantes, agentes quelantes, utilização de certas vitaminas, a partir de medicamentos fitoterápicos, homeopáticos ou células tronco.

\subsubsection{Agentes Quelantes}

Os quelantes de ferro exibem efeitos quelantes de ferro, antivirais e imunomoduladores in vitro e in vivo, particularmente contra vírus de RNA. Esses agentes podem atenuar a Síndrome do Desconforto Respiratório Agudo (SDRA) e ajudar a controlar o SARS-CoV-2 por meio de múltiplos mecanismos, incluindo: 1) inibição da replicação viral; 2) diminuição da disponibilidade de ferro; 3) regulação positiva de células B; 4) melhoria do título de anticorpo antiviral neutralizante; 5) inibição da inflamação endotelial; e 6) prevenção de fibrose pulmonar $e$ declínio pulmonar via redução do acúmulo pulmonar de ferro (DALAMAGA; KARAMPELA; MANTZOROS, 2020). 


\subsubsection{Vitamina $D$}

Para reduzir o risco de infecção pelo SARS-CoV-2, Grant et al. (2020) recomendam que as pessoas em risco de influenza e/ou COVID-19 considerem tomar $10.000 \mathrm{UI} /$ dia de vitamina D por algumas semanas para aumentar rapidamente as concentrações de 25-hidróxi- vitamina D (25OHD), seguidas por $5.000 \mathrm{UI} /$ dia. O objetivo é aumentar as concentrações de 25OHD acima de 40-60 ng/mL (100-150 nmol/L). Para o tratamento de pessoas infectadas com COVID-19, doses mais elevadas de vitamina D podem ser úteis.

\subsubsection{Medicamentos Fitoterápicos Tradicionais Chineses (CHM)}

Os ingredientes ativos (Fórmula A: Rhizoma Atractylodis, Flos Lonicerae, Pericarpium Citri Reticulatae, Rhizoma Phragmitis, Folium Mori e Radix Astragali Hedysari; e Fórmula B: Radix Astragali Hedysari, Rhizoma Atractylodis Macrocephalae, Radix Saposhnikoviae, Cyrtomium fortunei J. Sm., Flos Lonicerae, Eupatorium fortunei Turcz. e Pericarpium Citri Reticulatae) e os alvos de ação das fórmulas de Medicamentos Fitoterápicos Tradicionais Chineses (CHM) obtidos no Banco de Dados de Farmacologia da Medicina Tradicional Chinesa e da Plataforma de Análise (TCMSP) tiveram um papel positivo na prevenção da COVID-19 e justificam uma aplicação adicional. Essa pesquisa fornece novas evidências para apoiar o possível valor das fórmulas CHM para a prevenção da COVID-19 (YU; WANG; SHEN, 2020).

\subsubsection{Células-tronco}

O potencial das células-tronco mesenquimais do cordão umbilical expandido (UC-MSCs) pode ser uma estratégia terapêutica evolutiva no gerenciamento da doença por COVID-19. Isso impediria a tempestade de citocinas, já que estas podem induzir danos aos órgãos seguidos por edema, disfunção das trocas aéreas, lesão cardíaca aguda e infecção secundária, o que pode levar à morte (ORLEANS; IS VICE; MANCHIKANTI, 2020).

\subsubsection{Homeopatia}

Na homeopatia, o arsênico em concentração muito baixa é considerado benéfico para várias doenças, incluindo infecções virais. Recentemente, a Diretoria de AYUSH, Nova Delhi, Índia, emitiu uma ordem, datada de 30 de janeiro de 2020, para tomar medicamentos profiláticos e, assim, evitar a infecção por coronavírus. A diretoria sugeriu tomar quatro comprimidos do medicamento Arsênico Album-30 uma vez ao dia com o estômago vazio por três dias. O Arsênico Album-30 é um trióxido de arsênio altamente diluído e funciona como profilaxia homeopática. É importante mencionar aqui que não há evidência clínica para o medicamento Arsênico Album-30 como um medicamento eficaz, mas esta se mostra como uma hipótese alternativa (ALI; ALHARBI, 2020). 


\subsection{COVID-19 no Brasil}

No Brasil, o primeiro caso confirmado de infecção pelo SARS-COV-2 foi registrado em 26 de fevereiro de 2020 na cidade de São Paulo, desde então, a quantidade de infectados e de mortos cresce a cada a dia. A última atualização, realizada às 19 horas do dia 23 de julho de 2020, mostra que existem 2.287.475 casos confirmados de COVID-19 e 84.082 números de óbitos registrados (BRASIL, 2020a).

Atualmente, os protocolos do Ministério da Saúde para o tratamento da infecção são determinados de acordo com os sinais e os sintomas apresentados pelos pacientes, que podem ser divididos em leves moderados ou graves (BRASIL, 2020b).

Leves: anosmia, ageusia, coriza, diarreia, dor abdominal, febre, mialgia, tosse, fadiga $e$ cefaleia.

Moderados: tosse persistente + febre persistente diária OU tosse persistente + piora progressiva de outro sintoma relacionado à COVID-19 OU pelo menos um dos sintomas supracitados + presença de fator de risco.

Graves: síndrome respiratória aguda grave - dispneia/desconforto OU pressão persistente no tórax OU saturação menor que $95 \%$ em ar ambiente OU coloração azulada de lábios ou rosto.

No Quadro 3 estão determinados os sinais e os sintomas com os respectivos tratamentos farmacológicos utilizados para pacientes adultos no Brasil.

Quadro 3 - Tratamento farmacológico para COVID-19 de acordo com os sinais e os sintomas

\begin{tabular}{|c|c|}
\hline Sinais e Sintomas & Tratamento farmacológico \\
\hline Leves & Difosfato de Cloroquina + Azitromicina \\
ou \\
Sulfato de Hidroxicloroquina + Azitromicina
\end{tabular}

Fonte: Adaptado de Brasil (2020b)

Vale ressaltar que é de fundamental importância que sejam realizados estudos no Brasil para avaliar a utilização desses medicamentos, visto que há alteração na farmacocinética e na farmacodinâmica entre a população e de acordo com a idade, pois, apesar de que os estudos realizados em outros países sejam muito relevantes, é preciso estudar e mensurar a terapia farmacológica e sua eficiência no país para que esses sejam aplicados de melhor maneira nos pacientes. Uma vez que a quantidade de casos confirmados e de óbitos no Brasil só aumentam desde o dia do primeiro teste positivo, é indispensável que haja maiores investimentos em pesquisas, a fim de acelerar a descoberta do tratamento e a profilaxia eficaz (SEVILLA-SÁNCHEZ; TUSET-CREUS, 2020).

No Brasil, houve aumento significativo na comercialização de alguns medicamentos à medida que novas notícias sobre estudos com as drogas iam sendo divulgadas, o que gerou a criação de novas normativas de controle relativas à comercialização desses medicamentos (CFF, 2020). Na Figura 2 está representada a proporção de aumento da comercialização de alguns 
princípios ativos, relacionando os valores do primeiro trimestre de 2019 e com os do primeiro trimestre de 2020.

Figura 2 - Aumento da comercialização de princípios ativos, relação 2019/2020

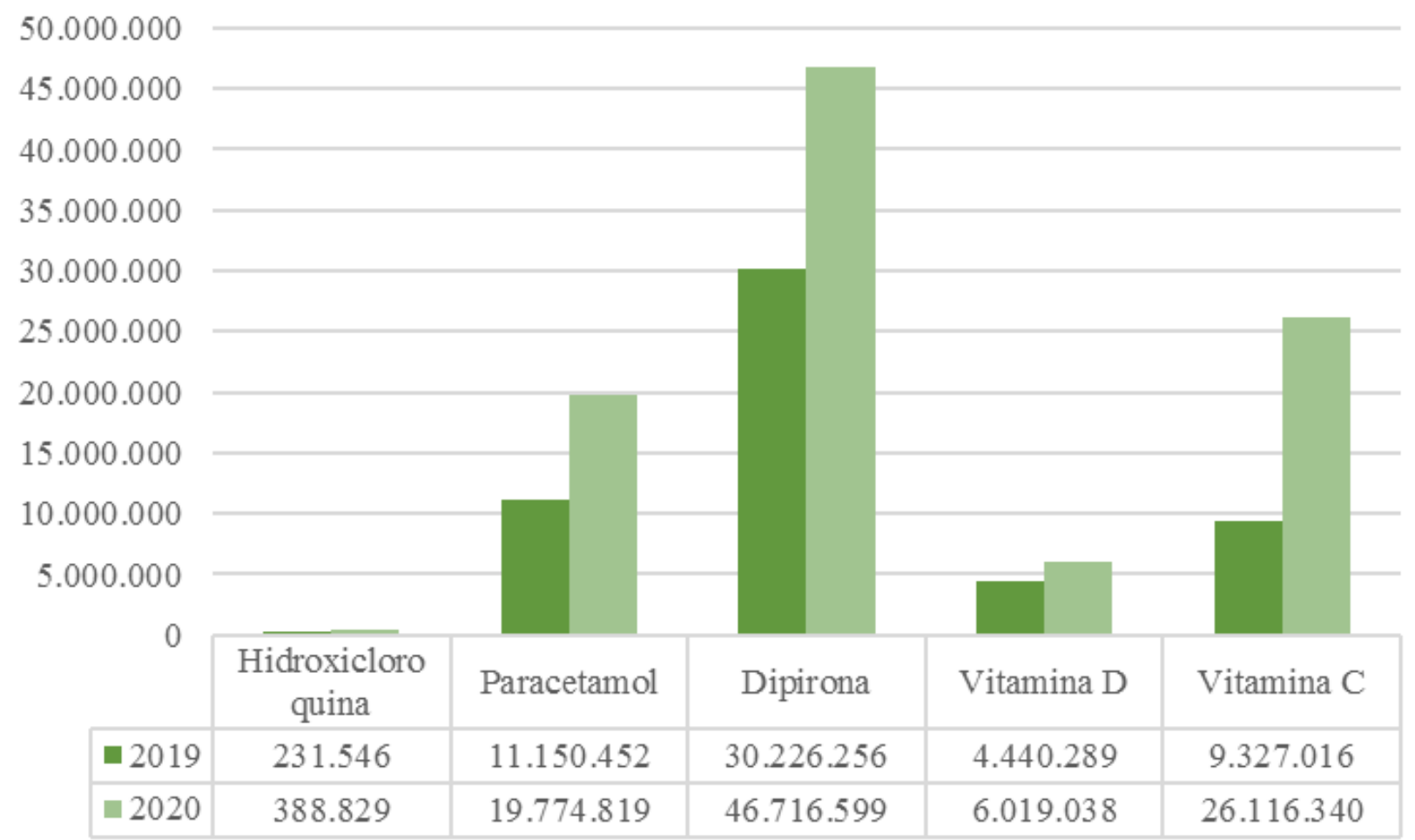

Fonte: Adaptada de CFF (2020)

Como visto na Figura 2, houve um aumento considerável na venda de medicamentos no primeiro trimestre de 2020, e a automedicação tem sido algo recorrente, isso demonstra que é uma prática que precisa ser cada vez mais discutida. O uso de medicamentos de forma indiscriminada pode acarretar diversos riscos à saúde do paciente. Esses riscos podem incluir a aparição de efeitos adversos graves causados a partir da ingestão de quantidades incorretas desses medicamentos, como é o caso da Hidroxicloroquina que, em overdose, pode causar hipotensão, arritmias, hipocalemia, bloqueio atrioventricular, coma, entre outros sintomas (WONG, 2020). Outro príncipio ativo muito comercializado foi a Vitamina C, que, a partir do seu uso prolongado, pode causar diarreias, cólicas, dor abdominal e dor de cabeça (CFC, 2020).

\section{Considerações Finais}

Vários fármacos estão sendo utilizados no tratamento da COVID-19, que são: Redemsivir, Favipiravir, Ribavirina, Arbidol, Hidroxicloroquina, Azitromicina, Interferon beta-1b e associação entre Lopinavir/Ritonavir. Esses medicamentos atuam em diferentes alvos no vírus, entre eles, é possível destacar a inibição da RNA polimerase dependente, que é o alvo mais recorrentemente encontrado no tratamento dessa enfermidade, $e$, entre os fármacos que agem por esse mecanismo, destaca-se o Remdesivir. Outros mecanismos incluem inibição da: fusão do vírus com a membrana da célula alvo, acidificação endossômica, exocitose viral e protease do tipo papaína e protease do tipo 3C. A associação entre essas drogas potencializa o efeito antiviral, 
sendo uma estratégia bastante adotada. Além disso, várias hipóteses alternativas também estão sendo utilizadas como terapias complementares potenciais para o tratamento da COVID-19, mas ainda existe a necessidade de averiguação destas para avaliar a sua segurança e eficácia, além disso são necessários estudos clínicos controlados.

Muitos dos pacientes com COVID-19 apresentam outras complicações fisiológicas, o que pode alterar a farmacocinética e a farmacodinâmica dos medicamentos, de forma a causar comprometimento em suas concentrações sanguíneas e, posteriormente, aumentar o risco de superdosagem e toxicidade. Dessa forma, as indicações farmacológicas devem ser bem avaliadas, além de levar em consideração as peculiaridades de cada paciente e o estágio da doença, já que muitos fármacos utilizados na remediação da COVID-19 necessitam de ajustes de dose e de contínuo monitoramento. Vale ressaltar que existem repercussões negativas na divulgação de medicamentos/tratamentos antes de se ter os resultados de grandes e robustos ensaios clínicos disponíveis, pois as pessoas podem começar a prática da automedicação e, potencialmente, desenvolverem sérios riscos, o que reforça a necessidade de controlar a divulgação de estudos em andamento por meio das mídias.

Durante a pandemia da COVID-19, deve-se continuar a defender a medicina baseada em evidências de alta qualidade para informar o manejo dos pacientes, deixando-os cientes da toxicidade que alguns tratamentos podem causar. Sendo assim, é importante que haja uma adequação dos estudos acerca da utilização desses medicamentos em cada país, especialmente no Brasil, de acordo com disponibilidade dos fármacos em cada território, pois, por se tratar de um problema de saúde pública mundial, isso poderia contribuir para a diminuição dos custos do tratamento. É importante também que haja a continuidade dos estudos a partir de desenhos metodológicos mais rígidos e de forma mais abrangente para que essa situação seja enfrentada de forma mais eficiente e eficaz e sem maiores perdas para a sociedade.

\section{Perspectivas Futuras}

Centenas de milhões de vidas foram afetadas pela pandemia da COVID-19 que sobrecarregou os sistemas nacionais de saúde e trouxe consequências consideráveis na economia global, o que pode se agravar ainda mais se a disseminação e a virulência do SARS-CoV-2 não forem contidas ou se os tratamentos eficazes não forem desenvolvidos. Portanto, ressalta-se a importância de um estudo como este, tanto para atualizar os dados sobre a temática quanto para estimular o desenvolvimento de novas pesquisas nesse âmbito, expondo resultados de estudos dos medicamentos mais utilizados no tratamento dessa enfermidade.

Considerando a ameaça global à saúde causada pelo SARS-CoV-2, a prevenção e o tratamento eficazes da pneumonia COVID-19 serão urgentemente necessários. No entanto, o desenvolvimento de medicamentos para o SARS-CoV-2 patogênico ainda é um grande problema para os humanos e, atualmente, não há medicamentos oficialmente aprovados para o tratamento de COVID-19. Dadas as características epidemiológicas do SARS-CoV-2, é fundamental interromper a propagação do vírus por meio de métodos de prevenção e controle de epidemias, por exemplo, isolando pacientes infectados e controlando a fonte de infecção (LI et al., 2020). Devido à ausência de tratamento efetivo ou de vacinas contra a COVID-19, as medidas de precaução são a única forma de enfrentar essa crise neste momento. 
Além de desenvolver novos medicamentos e ensaios clínicos de medicamentos antigos, o desenho e o desenvolvimento de vacinas para SARS-CoV-2 também são necessários. As lições do SARS-CoV e do MERS-CoV sugerem que a pesquisa do SARS-CoV-2 deve se concentrar no estabelecimento de modelos animais que recapitulem os vários aspectos da doença humana e os determinantes da segurança e eficácia da vacina (LI et al., 2020).

O aprimoramento dos programas de desenvolvimento de drogas deve ser realizado e serviria para identificar e estabelecer testes pré-clínicos de moléculas candidatas eficazes contra coronavírus, bem como outros vírus zoonóticos. Esperançosamente, em 2020, as lições aprendidas com a epidemia da COVID-19 irão estimular um esforço global colaborativo e um maior foco em como controlar melhor as futuras pandemias e o desenvolvimento de novos medicamentos e vacinas para combater doenças zoonóticas em potencial (TRIGGLE et al., 2020).

Para determinar as reais consequências do quadro da COVID-19, é imprescindível a realização de estudos de acompanhamento dos pacientes, o que ajudará a determinar as doenças em estágios iniciais e permitir a intervenção médica em tempo hábil. Ainda, isso poderia fornecer dados comparativos suficientes entre pacientes em todo o mundo para determinar os efeitos da COVID-19 em diferentes populações. Uma análise comparativa pode avaliar as semelhanças e as diferenças entre os pacientes em todo o mundo, o que pode ser benéfico se uma determinada população tem uma vantagem adicional em termos de imunidade durante o combate ao vírus (BALACHANDAR et al., 2020).

\section{Referências}

ALI, I.; ALHARBI, O.M.L. COVID-19: Disease, management, treatment, and social impact. Sci Total Environ, [S.l.], v. 728, p. 138861, 2020. DOI:10.1016/j.scitotenv.2020.138861.

ANTINORI, S. et al. Compassionate remdesivir treatment of severe Covid-19 pneumonia in intensive care unit (ICU) and Non-ICU patients: Clinical outcome and differences in posttreatment hospitalisation status. Pharmacol Res., [S.l.], v. 158, p. 104899, 2020. DOI:10.1016/j. phrs.2020.104899.

ARSHAD, S. et al. Treatment with hydroxychloroquine, azithromycin, and combination in patients hospitalized with COVID-19. Int J Infect Dis., [S.I.], v. 97, p. 396-403, 2020. DOI:10.1016/j. ijid.2020.06.099.

BALACHANDAR, Vellingiri et al. Follow-up studies in COVID-19 recovered patients-is it mandatory? Science of The Total Environment, [S.I.], p. 139021, 2020. DOI: 10.1016/j. scitotenv.2020.139021.

BRASIL. Painel de casos de doença pelo coronavírus 19 (COVID-19) no Brasil pelo Ministério da Saúde. Brasília, DF: Ministério da Saúde, 2020a. Disponível em: https://covid.saude. gov.br/. Acesso em: 24 jul. 2020.

BRASIL. Orientações do Ministério da Saúde para manuseio medicamentoso precoce de pacientes diagnosticados da COVID-19. Brasília (DF): Ministério da Saúde, 2020b. Disponível em: https://saude.gov.br/images/pdf/2020/June/18/COVID-FINAL-16JUNHO-LIvreto-1-V3.pdf. Acesso em: 24 jul. 2020. 
CAI, Qingxian et al. Experimental treatment with favipiravir for COVID-19: an open-label control study. Engineering, [S.l.], v. 10, p. 1016, 2020. DOI: 10.1016/j.eng.2020.03.007.

CAO, Bin et al. A Trial of Lopinavir-Ritonavir in Adults Hospitalized with Severe Covid-19. New England Journal of Medicine, [S.l.], v. 382, n. 19, p. 1.787-1.799, 2020. DOI: 10.1056/ NEJMoa2001282.

CFF - CONSELHO FEDERAL DE FARMÁCIA. Levantamento mostra como o medo da Covid-19 impactou venda de medicamentos. 2020. Disponível em: https:/www.cff.org.br/noticia. php?id=5747. Acesso em: 24 ago. 2020.

COOMES, E. A.; HAGHBAYAN, H. Favipiravir, an antiviral for COVID-19? The Journal of Antimicrobial Chemotherapy, [S.I.], v. 75, n. 7, p. 2.013-2.014, 2020. DOI: 10.1093/jac/dkaa171.

COENEN, Samuel et al. Oseltamivir for coronavirus illness: post-hoc exploratory analysis of an open-label, pragmatic, randomised controlled trial in European primary care from 2016 to 2018. British Journal of General Practice, [S.I.], v. 70, n. 696, p. e444-e449, 2020. DOI:10.3399/ bjgp20X711941.

CRODA, Julio et al. COVID-19 in Brazil: advantages of a socialized unified health system and preparation to contain cases. Rev. Soc. Bras. Med. Trop., Uberaba, v. 53, e. 20200167, 2020. DOI: 10.1590/0037-8682-0167-2020.

DALAMAGA, M.; KARAMPELA, I.; MANTZOROS, C. S. Commentary: Could iron chelators prove to be useful as an adjunct to COVID-19 Treatment Regimens? Metabolism: Clinical and Experimental, [S.l.], v. 108, p. 154-260, 2020. DOI: 10.1016/j.metabol.2020.154260.

DE SOUZA MORAIS, Williams Raphael et al. Investigação Prospectiva do Novo Coronavírus e de Fármacos Antivirais com Potencial Atividade Terapêutica para o Tratamento de Pacientes Infectados pela COVID-19. Cadernos de Prospecção, Salvador, v. 13, n. 3, p. 619, 2020. DOI: 10.9771/ cp.v13i3.36384.

DENG, L. et al. Arbidol combined with LPV/r versus LPV/r alone against Corona Virus Disease 2019: A retrospective cohort study. J Infect., [S.l.], v. 81, n. 1, p. e1-e5, 2020. DOI: 10.1016/j. jinf.2020.03.002.

DU, Y. X.; CHEN, X. P. Favipiravir: Pharmacokinetics and Concerns About Clinical Trials for 2019nCoV Infection. Clinical Pharmacology and Therapeutics, [S.1.], v. 108, n. 2, p. 242-247, 2020. DOI: $10.1002 /$ cpt.1844.

EASTMAN, R. T. et al. Remdesivir: A Review of Its Discovery and Development Leading to Emergency Use Authorization for Treatment of COVID-19. ACS Central Science, [S.I.], v. 6, n.5, p. 672-683, 2020. DOI: 10.1021/acscentsci.0c00489.

ESPOSITO, S.; NOVIELLO, S.; PAGLIANO, P. Update on treatment of COVID-19: ongoing studies between promising and disappointing results. Le Infezioni Med, [S.I.], v. 2, p. 198-211, 2020.

GAUTRET, Philippe et al. Clinical and microbiological effect of a combination of hydroxychloroquine and azithromycin in 80 COVID-19 patients with at least a six-day follow up: a pilot observational study. Travel Medicine and Infectious Disease, [S.I.], n. 34, p. 101-663, 2020. DOI: 10.1016/j. tmaid.2020.101663. 
GRANT, William B. et al. Evidence that vitamin D supplementation could reduce risk of influenza and COVID-19 infections and deaths. Nutrients, [S.I.], v. 12, n. 4, p. 988, 2020. DOI: 10.3390/ nu12040988.

GREIN, Jonathan et al. Compassionate Use of Remdesivir for Patients with Severe Covid-19. The New England Journal of Medicine, [S.l.], v. 382, n. 24, p. 2.327-2.336, 2020. DOI: 10.1056/ NEJMoa2007016.

GUL, M. H. et al. Potential specific therapies in COVID-19. Therapeutic Advances in Respiratory Disease, [S.I.], v. 14, 2020. DOI: 10.1177/1753466620926853.

HUNG, Ivan Fan-Ngai et al. Triple combination of interferon beta-1b, lopinavir-ritonavir, and ribavirin in the treatment of patients admitted to hospital with COVID-19: an open-label, randomised, phase 2 trial. The Lancet, [S.I.], v. 395, n. 10238, p. 1.695-1.704, 2020. DOI: 10.1016/S0140-6736(20)31042-4.

JEAN, S. S.; LEE, P. I.; HSUEH, P. R. Treatment options for COVID-19: The reality and challenges. Journal of Microbiology, Immunology, and Infection $=$ Wei mian yu gan ran za zhi, [S.l.], v. 53, n. 3, p. 436-443, 2020. DOI: 10.1016/j.jmii.2020.03.034.

KHALILI, J. S. et al. Novel coronavirus treatment with ribavirin: Groundwork for an evaluation concerning COVID-19. J Med Virol., [S.I.], v. 92, n. 7, p. 740-746, 2020. DOI: 10.1002/jmv.25798.

LI, Heng et al. Coronavirus disease 2019 (COVID-19): current status and future perspective. International Journal of Antimicrobial Agents, [S.l.], v. 55, n. 5, p. 105951, 2020. DOI: $10.1016 /$ j.ijantimicag.2020.105951.

LIPWORTH, B.; KUO, C. R.; CHAN, R. Emerging pharmacotherapy for COVID-19. The journal of the Royal College of Physicians of Edinburgh, [S.l.], v. 50, n. 2, p. 133-137, 2020. DOI:10.4997/ JRCPE.2020.210.

LIU, Fang et al. Intravenous high-dose vitamin C for the treatment of severe COVID-19: study protocol for a multicentre randomised controlled trial. BMJ Open, [S.I.], v. 10, n. 7, p. e039519, 2020. DOI: 10.1136/bmjopen-2020-039519.

LU, C. C. et al. Potential therapeutic agents against COVID-19: What we know so far. Journal of the Chinese Medical Association: JCMA, [S.I.], v. 83, n. 6, p. 534-536, 2020. DOI: 10.1097/ JCMA.0000000000000318.

LU, I. N. et al. MuLTi-Arm Therapeutic study in pre-ICu patients admitted with Covid-19Experimental drugs and mechanisms (TACTIC-E): A structured summary of a study protocol for a randomized controlled trial. Trials, [S.I.], v. 21, n. 1, p. 690, 2020. DOI: 10.1186/s13063-02004618-2.

ORLEANS, L. A.; IS VICE, H.; MANCHIKANTI, L. Expanded umbilical cord mesenchymal stem cells (UC-MSCs) as a therapeutic strategy in managing critically ill COVID-19 patients: the case for compassionate use. Pain Physician, [S.l.], v. 23, p. E71-E83, 2020.

PANTOS, Constantinos et al. Triiodothyronine for the treatment of critically ill patients with COVID-19 infection: A structured summary of a study protocol for a randomised controlled trial. Trials, [S.l.], v. 21, n. 1, p. 1-3, 2020. DOI:10.1186/s13063-020-04474-0.

PILKINGTON, Victoria; PEPPERRELL, Toby; HILL, Andrew. A review of the safety of favipiravir-a potential treatment in the COVID-19 pandemic? Journal of Virus Eradication, [S.I.], v. 6, n. 2, p. 45, 2020. DOI: 10.1016/S2055-6640(20)30016-9. 
PLAZE, M. et al. Repurposing chlorpromazine to treat COVID-19: The reCoVery study. Encephale, [S.l.], v. 46, n. 3, p.169-172, 2020. DOI:10.1016/j.encep.2020.05.006.

QUINTELLA, Cristina M. et al. Fármacos para COVID-19: muito além da cloroquina (testes clínicos para o coronavírus SARS-CoV-2). Cadernos de Prospecção, Salvador, v. 13, n. 3, p. 599, 2020. DOI: $10.9771 /$ cp.v13i3.36815.

ROSA, S. G. V.; SANTOS, W. C. Ensayos clínicos de reposicionamiento de medicamentos para el tratamiento de la COVID-19. Revista Panamericana de Salud Pública, [S.1.], v. 44, n.40, p. 1-7, 2020. DOI: $10.26633 /$ RPSP.2020.40.

SAHA, A. et al. Probable Molecular Mechanism of Remdesivir for the Treatment of COVID-19: Need to Know More. Archives of Medical Research, [S.I.], S0188-4409 n. 20, p. 30699-8, 2020. Advance online publication. DOI: 10.1016/j.arcmed.2020.05.001.

SANDERS, J. M. et al. Pharmacologic treatments for coronavirus disease 2019 (COVID-19): a review. Jama, [S.I.], v. 323, n. 18, p. 1.824-1.836, 2020. DOI: 10.1001/jama.2020.6019.

SEVILLA-SÁNCHEZ, D.; TUSET-CREUS, M. La atención farmacéutica en pacientes ingresados. Revista Farmacia Hospitalaria, [S.I.], v. 44, n. 1, p. 28-31, 2020. DOI: https://doi:10.7399/ fh. 11513 .

SILVA, Francielle Santos da et al. Evaluation of recombinant human interferon beta $1 \mathrm{~b}$ by liquid chromatography methods and bioassay. Braz. J. Pharm. Sci., São Paulo, v. 55, p. 18328, 2019. DOI: $10.1590 / s 2175-97902019000218328$.

ŞIMŞEK YAVUZ, S.; ÜNAL, S. Tratamento antiviral de COVID-19. Turk J Med. Sci., [S.l.], v. 50 n. 1, p. 611-619, 2020. Published 2020 Apr 21. DOI: 10.3906 / sag-2004-145.

SIRBU, Carmen Adella et al. Active Pulmonary Tuberculosis Triggered by Interferon Beta-1b Therapy of Multiple Sclerosis: Four Case Reports and a Literature Review. Medicina, [S.I.], v. 56, n. 4, p. 202, 2020. DOI: 10.3390/medicina56040202.

TANG, Wei et al. Hydroxychloroquine in patients with mainly mild to moderate coronavirus disease 2019: open label, randomised controlled trial. BMJ (Clinical Research ed.), [S.l.], n. 369, p.1849, 2020. DOI: $10.1136 /$ bmj.m1849.

TRIGGLE, Chris R. et al. COVID-19: Learning from Lessons To Guide Treatment and Prevention Interventions. Msphere, [S.I.], v. 5, n. 3, 2020. DOI:10.1128/mSphere.00317-20.

VANKADARI, Naveen. Arbidol: a potential antiviral drug for the treatment of SARS-CoV-2 by blocking the trimerization of viral spike glycoprotein?. International Journal of Antimicrobial Agents, [S.l.], v. 56, n. 2, p. 105998, 2020. DOI:10.1016/j.ijantimicag.2020.105998.

WANG, Huihui et al. The genetic sequence, origin, and diagnosis of SARS-CoV-2. European journal of clinical microbiology \& infectious diseases: official publication of the European Society of Clinical Microbiology, [S.l.], v. 39, n. 9, 1629-1635, 2020. DOI:10.1007/s10096-02003899-4.

WANG, Yeming et al. Remdesivir in adults with severe COVID-19: a randomised, double-blind, placebo-controlled, multicentre trial. Lancet (London, England), [S.I.], v. 395 n. 10236, 15691578, 2020. DOI: 10.1016/S0140-6736(20)31022-9. 
WILKINSON, Tom et al. ACCORD: A Multicentre, Seamless, Phase 2 Adaptive Randomisation Platform Study to Assess the Efficacy and Safety of Multiple Candidate Agents for the Treatment of COVID-19 in Hospitalised Patients: A structured summary of a study protocol for a randomised controlled trial. Trials, [S.I.], v. 21, n. 1, p. 1-3, 2020. DOI:10.1186/s13063-020-04584-9.

WONG, Anselm. COVID-19 e toxicidade de tratamentos potenciais: Panaceia ou veneno. Medicina de emergência Australasia: EMA, [S.I.], v. 32, n. 4, 697-699, 2020. DOI:10.1111/17426723.13537

YE, Qingsong et al. Safety and efficacy assessment of allogeneic human dental pulp stem cells to treat patients with severe COVID-19: structured summary of a study protocol for a randomized controlled trial (Phase I/II). Trials, [S.l.], v. 21, n. 1, p. 1-4, 2020. DOI:10.1186/s13063-020-04380-5.

YE, X. T. et al. Clinical efficacy of lopinavir/ritonavir in the treatment of Coronavirus disease 2019. Eur Rev Med Pharmacol Sci, [S.l.], v. 24, n. 6, p. 3390-3396, 2020. DOI:10.26355/ eurrev_202003_20706.

YU, S.; WANG, J.; SHEN, H. Network pharmacology-based analysis of the role of traditional Chinese herbal medicines in the treatment of COVID-19. Annals of Palliative Medicine, [S.l.], v. 9, n. 2, p. 437-446, 2020. DOI: 10.21037/apm.2020.03.27.

ZHAI, Pan et al. The epidemiology, diagnosis and treatment of COVID-19. Int J Antimicrob Agents, [S.l.], v. 55, n. 5, p. 105-955, 2020. DOI: 10.1016/j.ijantimicag.2020.105955.

ZHENG, J. SARS-CoV-2: an Emerging Coronavirus that Causes a Global Threat. International Journal of Biological Sciences, [S.l.], v. 16, n. 10, p. 1.678-1.685, 2020. DOI: 10.7150/ ijbs. 45053.

ZHU, Z. et al. Arbidol monotherapy is superior to lopinavir/ritonavir in treating COVID-19. The Journal of Infection, [S.l.], v. 81, n.1, p. e21-e23, 2020. DOI:10.1016/j.jinf.2020.03.060.

\section{Sobre os Autores}

\section{Irineu Ferreira da Silva Neto}

E-mail: yrineuferreira@gmail.com

Discente do curso de Farmácia na Faculdade de Medicina Estácio de Juazeiro do Norte, Ceará.

Endereço profissional: Faculdade de Medicina Estácio de Juazeiro do Norte, Avenida, R. Ten. Raimundo Rocha, n. 515, Cidade Universitária, Juazeiro do Norte, CE. CEP: 63040-360.

\section{Isadora Ellen Feitoza Ricardino}

E-mail: isadoraricardino@gmail.com

Discente do curso de Farmácia na Faculdade de Medicina Estácio de Juazeiro do Norte, Ceará.

Endereço profissional: Faculdade de Medicina Estácio de Juazeiro do Norte, Avenida, R. Ten. Raimundo Rocha, n. 515, Cidade Universitária, Juazeiro do Norte, CE. CEP: 63040-360. 


\section{Maria Nathalya Costa Souza}

E-mail: nathalya535@hotmail.com

Discente do curso de Farmácia na Faculdade de Medicina Estácio de Juazeiro do Norte, Ceará.

Endereço profissional: Faculdade de Medicina Estácio de Juazeiro do Norte, Avenida, R. Ten. Raimundo Rocha, n. 515, Cidade Universitária, Juazeiro do Norte, CE. CEP: 63040-360.

\section{Rafael de Carvalho Mendes}

E-mail: rafael.mendes@estacio.br

Mestrado em Microbiologia Médica pela Universidade Federal do Ceará em 2010.

Endereço profissional: Faculdade de Medicina Estácio de Juazeiro do Norte, Avenida, R. Ten. Raimundo Rocha, n. 515, Cidade Universitária, Juazeiro do Norte, CE. CEP: 63040-360. 